\title{
REVIEWS
}

\section{The Role of Host-derived Dentinal Matrix Metalloproteinases in Reducing Dentin Bonding of Resin Adhesives}

\author{
Shan-chuan Zhang, Matthias Kern*
}

Department of Prosthodontics, Propaedeutics and Dental Materials, Christians-Albrechts University, Kiel, Germany

\begin{abstract}
Shan-chuan Zhang, Matthias Kern. The Role of Dentinal Host-derived Matrix Metalloproteinases in Reducing Dentin Bonding of Resin Adhesives. International Journal of Oral Science, 1(4): 163-176, 2009

Dentin matrix metalloproteinases (MMPs) are a family of host-derived proteolytic enzymes trapped within mineralized dentin matrix, which have the ability to hydrolyze the organic matrix of demineralized dentin. After bonding with resins to dentin there are usually some exposed collagen fibrils at the bottom of the hybrid layer owing to imperfect resin impregnation of the demineralized dentin matrix. Exposed collagen fibrils might be affected by MMPs inducing hydrolytic degradation, which might result in
\end{abstract}

reduced bond strength.

Most MMPs are synthesized and released from odontoblasts in the form of proenzymes, requiring activation to degrade extracellular matrix components. Unfortunately, they can be activated by modern self-etch and etch-and-rinse adhesives. The aim of this review is to summarize the current knowledge of the role of dentinal host-derived MMPs in dentin matrix degradation. We also discuss various available MMP inhibitors, especially chlorhexidine, and suggest that they could provide a potential pathway for inhibiting collagen degradation in bonding interfaces thereby increasing dentin bonding durability.

Keywords dentin bonding, matrix metalloproteinases (MMPs), MMP inhibitors, chlorhexidine

\section{Introduction}

Dentin, a tough, stiff, composite biological structure, is similar to other calcified tissues such as bone or cementum. It is a collagen-based tissue comprising $30 \%$ (by volume) organic matrix, which consists of collagen ( $90 \%)$, non-collagenous proteins $(10 \%)$, and inorganic apatite crystallites embedded in an extracellular matrix (ECM). Type I collagen, the most abundant organic component of the ECM, is responsible for the tensile strength of dentin and for the biochemical properties of dentin (Linde, 1989; Butler et al., 2003). The noncollagenous proteins, such as proteoglycans (i.e., chondroitin-4/6-sulphate, decorin, biglycan, lumican, fibromodulin) (Embery et al., 2001; Milan et al.,
2005) and the small integrin-binding ligand N-linked glycoproteins (SIBLINGs, i.e., bone sialoprotein, osteopontin, dentin matrix protein-1, dentin sialophosphoprotein) play an important part in dentinogenesis including regulating and controlling crystal growth, fibrillogenesis, and mineralization (Moses et al., 2006). Both collagen fibrils and non-collagenous proteins are synthesized and secreted by odontoblasts, some of which can be detected in both predentin and mineralized mature dentin (Goldberg and Takagi, 1993; Linde and Goldberg, 1993).

There has been a marked acceleration in the development of dentin bonding in recent years. Commercial bonding systems require the application of acid conditioners (etch-and-rinse or self- 
etching adhesives) to achieve a superficial demineralization of dentin (van Meerbeek et al., 2003). The demineralized dentin matrix treated with phosphoric acid $\left(\mathrm{H}_{3} \mathrm{PO}_{4}\right)$ (Figure 1A), should be entirely infiltrated with the adhesive resin to form a so-called "hybrid layer" (Figure 1B) (Breschi et al., 2004; Toledano et al., 2002). The hybrid layer is a structure made up of type I collagen fibrils and proteoglycans (Breschi et al., 2003; Breschi et al., 2004) enveloped by polymer chains. Resin infiltration starts with the diffusion of solvated liquid monomers through gaps between collagen fibrils (Marshall et al., 1997). The fibrils are embedded in a matrix of proteoglycans which play a fundamental role in their maintenance and stabilization up to the level of dentin demineralization (Breschi et al., 2002).

Most dental adhesives have adhesive properties, that are good enough to counteract polymeriza- tion shrinkage and that produce high immediate bond strengths. However, the durability of bonding between adhesives and the dentin matrix is still a concern (De Munck et al., 2005; Hebling et al., 2005). Long-term dentin bonding has drawn considerable attention (Hashimoto et al., 2000), but yielded no satisfactory results, even for a relatively short bonding period of 6 months. Successful long-term bonding to dentin remains a challenge, requiring the favorable infiltration of demineralized dentin matrix with adhesive to form a perfect and stable hybrid layer (van Meerbeek et al., 2003). Many studies have shown that resindentin bonds created by contemporary hydrophilic dentin adhesives deteriorate over time (Sano et al., 1999; Hashimoto et al., 2000; Hashimoto et al., 2002; Takahashi et al., 2002; Hashimoto et al., 2003a; De Munck et al., 2003; Hashimoto et al., 2004; Yang et al., 2005). Morphological evidences
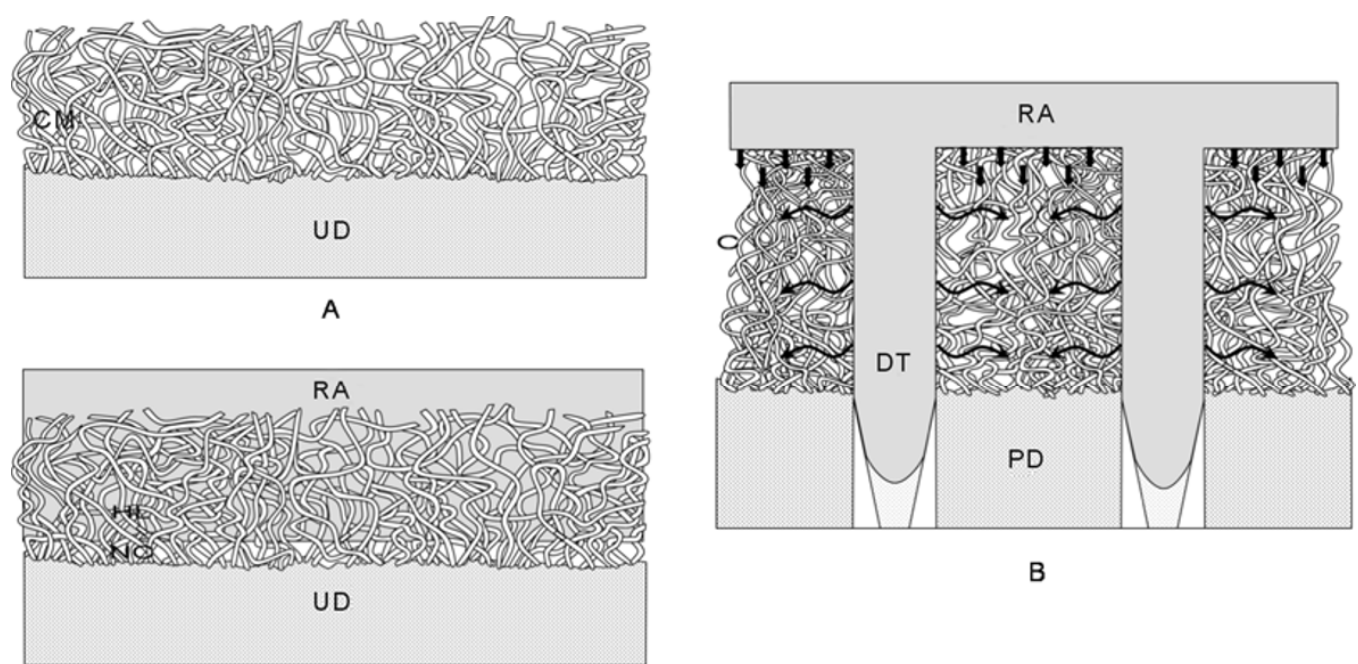

B

C
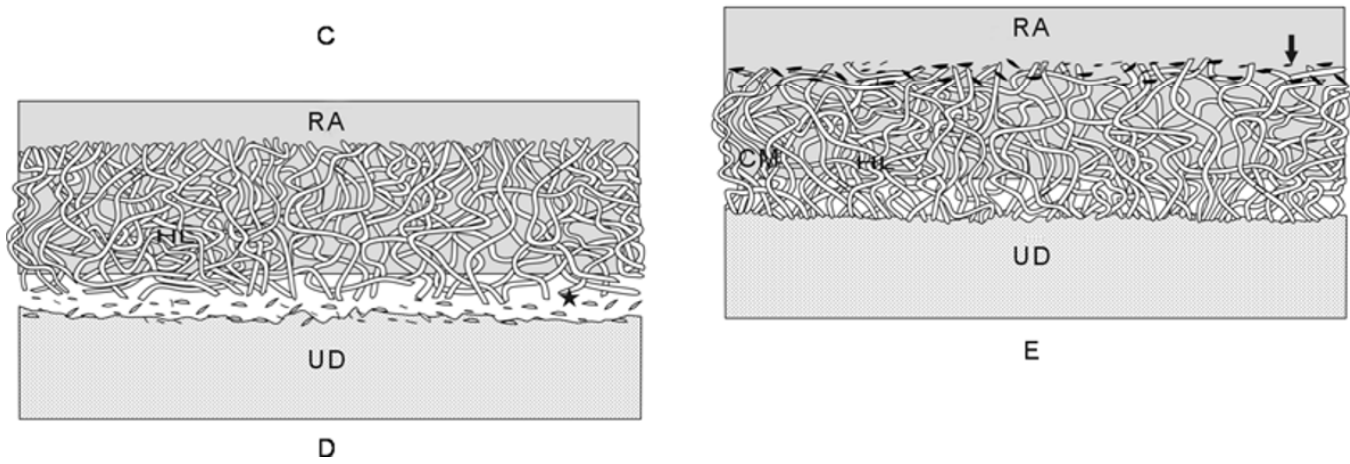

E

Figure 1 Schematic representation of dentin bonding of resin adhesive

(A): Demineralized dentin. UD: undemineralized dentin. CM: demineralized dentin collagen matrix. (B): The infiltration of resin adhesive into demineralized dentin. DT: dentinal tubule. RA: resin adhesive. PD: peritublar dentin. (C): Infiltrated dentin with resin adhesive. It shows the presence of a deficient resin infiltration. NC: nude collagen without the protection of resin adhesive. HL: hybrid layer. (D): After long-term artificial saliva storage. The nude collagen can be degraded( $\star$ ). (E): After long-term artificial saliva storage containing protease inhibitors. The demineralized dentin collagen matrix can be preserved, and crystallites (arrowheads) may deposite along the demineralized front. 
of hydrolytic degradation of dentin collagen matrices and/or resin elution in aged resin-dentin interfaces have been found in several in vivo studies (Sano et al., 1999; Takahashi et al., 2002; Hashimoto et al., 2003b).

For etch-and-rinse adhesives, the diffusion of resin monomer into the demineralized dentin shows a decreasing concentration gradient (Wang and Spencer, 2002). This results in unprotected and vulnerable collagen fibrils at the bottom of the hybrid layer (Figure 1C) (Armstrong et al., 2001; Hashimoto et al., 2002; Breschi et al., 2003; Pashley et al., 2004; Yang et al., 2005; Brackett et al., 2007; Brackett et al., 2009). Deficient resin infiltration (Figure 1C) was also observed in selfetch adhesive systems (Sano et al., 1995), despite the ability of these adhesives to etch and prime simultaneously. These water-filled interfibrillar spaces with uncovered collagen fibrils correspond to the sites of different modes of silver nanoleakage (Tay et al., 2002). They may be structurally unstable owing to the absence of resin protection within the hybrid layer over time (Yang et al., 2005), resulting in a reduced long-term bond strength. They may also become the sites for collagen hydrolysis by host-derived matrix metalloproteinase (MMP) enzymes (Pashley et al., 2004; Carrilho et al., 2007a).

It is widely accepted that the marketed resin adhesives contain high concentrations of ionic and hydrophilic resin monomers to enable bonding to wet dentin substrates, and to etch and bond simultaneously enamel and dentin. However, these same monomers have several undesirable effects. For example, they may produce permeable unstable resin matrices that are liable to water sorption, resin leaching and hydrolysis over time. These kinds of extrinsic degradation of the resin-dentin interface, which originate in the adhesive above the hybrid layers, take place over time simultaneously with intrinsic collagen degradation by MMPs, which originate from beneath the adhesive layers.

MMPs, which are a group of calcium- and zincdependent host-derived enzymes (Visse and Nagase, 2003), are trapped within the mineralized dentin matrix during tooth development (Tjäderhane et al., 1998a; van Strijp et al., 2003). They can hydrolyze components of the ECM (Brinckerhoff and Matrisian, 2002). These proteinases play a central role in several physiological processes, such as development, normal tissue remodeling, and angiogenesis. Dentinogenesis is a complicated developmental phenomenon requiring active extracellular enzymatic function of several different proteinases, mainly of the MMP family (MartinDe Las Heras et al., 2000; Tjäderhane et al., 2001). MMPs appear to be also involved in different pathological processes and in tumor progression (Visse and Nagase, 2003). Recent studies revealed the contributions of host-derived proteinases to the breakdown of the collagen matrices in the pathogenesis of dentin caries (Dayan et al., 1983; Tjäderhane et al., 1998a; Martin-De Las Heras et al., 2000; Sulkala et al., 2002; van Strijp et al., 2003) and periodontal disease (Lee et al., 1995), with potential and relevant implications for dentin bonding (Pashley et al., 2004).

The purpose of this review is to summarize the current knowledge of the role of dentinal hostderived MMPs in the reduction of dentin bonding and to suggest that MMP inhibitors could provide a potential pathway to inhibit collagen degradation in bonding interfaces and thereby increase dentin bonding durability.

\section{Structure, property and function of MMPs in dentin}

Recently, different MMP genes and their enzyme products and substrates have been identified in humans (Table 1). Generally, MMPs consist of a prodomain, a catalytic domain with a highly conserved zinc-binding site, a hinge region, and a hemopexin domain (Visse and Nagase, 2003) (Figure 2). The catalytic domain contains cysteinerich repeats that are necessary for the binding and cleaving activities of these proteolytic enzymes (Visse and Nagase, 2003). MMPs can degrade the components of ECMs, including fibrillar and nonfibrillar collagens, fibronectin, laminin, and basement membrane glycoproteins. In addition, they have several other properties, for example, their requirement for cleaving of the prodomain for activating the enzymes, their dependence on a zinc ion for their activity, the conservation of specific amino acid sequences, and the inhibition of their 
Table 1 List of known MMPs and their substrates (from Lynch and Matrisian, 2002)

\begin{tabular}{|c|c|c|c|}
\hline MMP & Alternative Names & ECM substrate & Non-matrix substrates \\
\hline MMP-1 & Collagenase-1 & $\begin{array}{l}\text { Collagen I / II/III/VII/X/XI, gelatin, entactin, aggrecan, } \\
\text { fibronectin, laminin, tenascin, vitronectin }\end{array}$ & $\begin{array}{l}\text { Perlecan, IGFBP-2/3, ProTNF- } \alpha \text {, } \alpha 1-A C \text {, } \\
\alpha 2-M G, \alpha 1-P I\end{array}$ \\
\hline MMP-2 & Gelatinase A & $\begin{array}{l}\text { Collagen I /III/IV/V /VII/X/XI, tenascin decorin, } \\
\text { gelatin, elastin, fibronectin, laminin, aggrecan, } \\
\text { vitronectin }\end{array}$ & $\begin{array}{l}\text { TGF- } \beta \text {, TGF- } \beta 2 \text {, IL-1 } \beta, \text { MCP-3, SDF-1, } \\
\text { IGFBP-3/5, TNF- } \alpha \text {, FGF-R1, } \alpha 1-A C, \alpha 1-P I\end{array}$ \\
\hline MMP-3 & Stromelysin-1 & $\begin{array}{l}\text { Collagen III/IV/V/VII/IX/X/XI, elastin, laminin, } \\
\text { fibronectin, gelatin, aggrecan entactin, decorin, } \\
\text { tenascin, vitronectin }\end{array}$ & $\begin{array}{l}\text { Perlecan, HB-EGF, IL-1 } \beta \text {, plasminogen, } \\
\text { E-cadherin, IGFBP-3, TNF- } \alpha, \alpha 1-A C \text {, } \\
\alpha 2-M G, \alpha 1-P I\end{array}$ \\
\hline MMP-7 & Matrilysin & $\begin{array}{l}\text { Collagen I /IV, aggrecan, laminin, fibronectin, } \\
\text { gelatin, entactin, decorin, elastin, tenascin, } \\
\text { vitronectin }\end{array}$ & $\begin{array}{l}\text { FASL, } \beta 4 \text { integrin, E-cadherin, HB-EGF, } \\
\text { plasminogen, TNF- } \alpha, \alpha 1-P I\end{array}$ \\
\hline MMP-8 & Collagenase-2 & Collagen I / II /III, aggrecan & a2-MG, a1-PI \\
\hline MMP-9 & Gelatinase B & $\begin{array}{l}\text { Collagen IV/V/XI/X IV, decorin, gelatin, elastin, } \\
\text { laminin, aggrecan, vitronectin }\end{array}$ & $\begin{array}{l}\text { TGF- } \beta 2 \text {, IL-1 } \beta, \text { TNF- } \alpha \text {, IL-2Ra, } \\
\text { plasminogen, } \alpha 1-A C, \alpha 2-M G, \alpha 1-P I\end{array}$ \\
\hline MMP-10 & Stromelysin-2 & $\begin{array}{l}\text { Collagen III/IV/V, aggrecan, elastin, laminin, } \\
\text { fibronectin, gelatin }\end{array}$ & ND \\
\hline MMP-11 & Stromelysin-3 & ND & IGFBP-1, $\alpha 2-M G, \alpha 1-P I$ \\
\hline MMP-12 & Metalloelastase & $\begin{array}{l}\text { Collagen I /IV, aggrecan, decorin, gelatin, elastin, } \\
\text { fibronectin, laminin, vitronectin, entactin }\end{array}$ & Plasminogen, $\alpha 2-M G, \alpha 1-P I$ \\
\hline MMP-13 & Collagenase- 3 & $\begin{array}{l}\text { Collagen I / II /III/VI/IX/X / X IV, gelatin, } \\
\text { fibronectin, aggrecan }\end{array}$ & a2-MG \\
\hline MMP-14 & MT1-MMP & $\begin{array}{l}\text { Collagen I / II /III, gelatin, fibronectin, laminin, } \\
\text { entactin, vitronectin, aggrecan }\end{array}$ & CD44, transglutaminase, $\alpha 2-M G, \alpha 1-P I$ \\
\hline MMP-15 & MT2-MMP & $\begin{array}{l}\text { Aggrecan, entactin, fibronectin, laminin, } \\
\text { tenascin }\end{array}$ & Transglutaminase \\
\hline MMP-16 & MT3-MMP & Collagen III, fibronectin, gelatin & Transglutaminase \\
\hline MMP-17 & MT4-MMP & Gelatin & $\alpha 2-M G, T N F-\alpha$ \\
\hline MMP-18 & $\begin{array}{l}\text { Collagenase-4 } \\
\text { (Xenopus) }\end{array}$ & Collagen I & ND \\
\hline MMP-19 & RASI & $\begin{array}{l}\text { Collagen I /IV, fibronectin, gelatin, tenascin, } \\
\text { laminin, aggrecan, entactin, COMP }\end{array}$ & ND \\
\hline MMP-20 & Enamelysin & Collagen X VIII, aggrecan, amelogenin, COMP & ND \\
\hline MMP-21 & XMMP (Xenopus) & No known substrates & ND \\
\hline MMP-22 & CMMP (chicken) & Gelatin & ND \\
\hline MMP-23 & $\begin{array}{l}\text { CA-MMP } \\
\text { (cysteine array MMP) }\end{array}$ & ND & ND \\
\hline MMP-24 & MT5-MMP & Collagen I, gelatin, fibronectin, laminin & ND \\
\hline MMP-25 & MT6-MMP & Collagen IV, gelatin, fibronectin & ND \\
\hline MMP-26 & $\begin{array}{l}\text { Matrilysin-2 } \\
\text { Endometase }\end{array}$ & Collagen IV, fibronectin, gelatin & a1-PI \\
\hline
\end{tabular}


Table 1 cont.

\begin{tabular}{cllll}
\hline MMP & Alternative Names & & ECM substrate & Non-matrix substrates \\
\hline MMP-27 & & ND & ND \\
MMP-28 & Epilysin & ND & ND \\
\hline
\end{tabular}

IGFBP: insulin like growth factor binding protein, TGF- $\beta$ : transforming growth factor- $\beta$, HB-EGF: heparin bound epidermal growth factor, IL: Interleukin, $\alpha 1$-AC: $\alpha 1$-anti-chymotrypsin, TNF- $\alpha$ : tumor necrosis factor- $\alpha, \alpha 2-\mathrm{MG}$ : $\alpha 2$-macroglobulin, $\alpha 1$-PI: $\alpha 1$-proteinase inhibitors, ND: not determined.

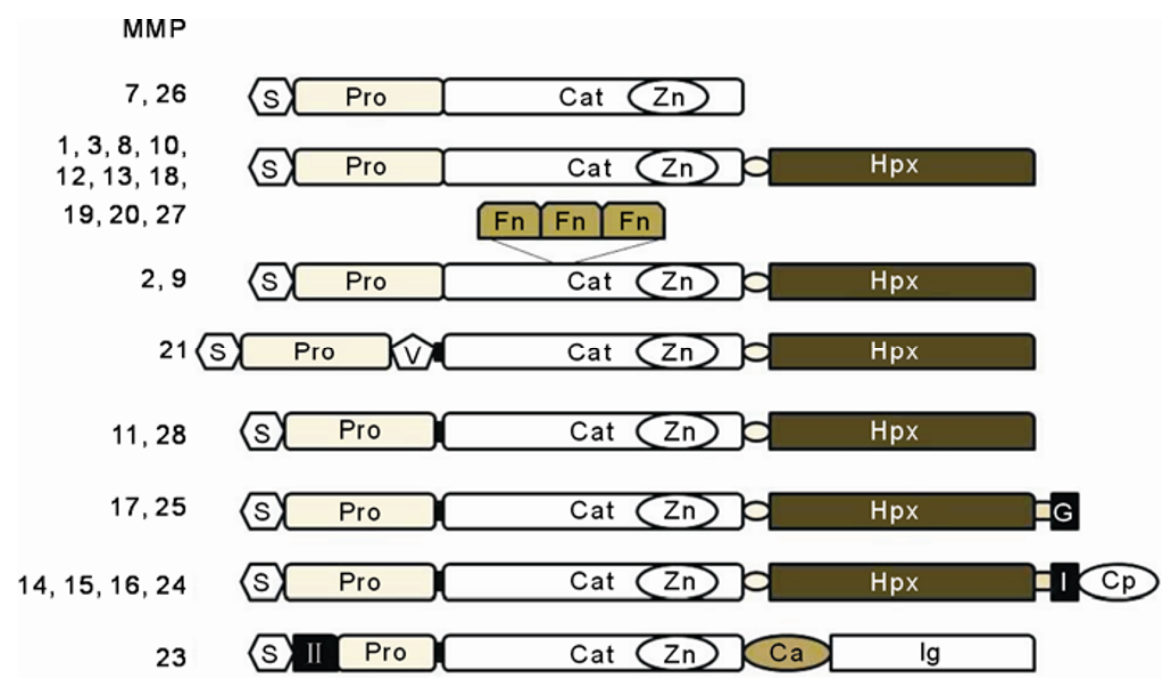

Figure 2 Domain organization of different MMPs (from Visse and Nagase, 2003)

The domain structure of MMPs is as indicated: S, signal peptide; Pro, propeptide; Cat, catalytic domain; Zn, active-site zinc; Hpx, hemopexin domain; Fn, fibronectin domain; V, vitronectin insert; I, type I transmembrane domain; II, type II transmembrane domain; G, GPI anchor; Cp, cytoplasmic domain; Ca, cysteine array region; and Ig, IgG-like domain. A furin cleavage site is depicted as a black band between the propeptide and the catalytic domain.

enzymatic activity by endogenous tissue inhibitors of metalloproteinases (TIMPs) (Birkedal-Hansen, 1993; Birkedal-Hansen et al., 1993; Nagase and Woessner, 1999). They are also characterized by a catalytic domain with cysteine-rich repeats necessary for the binding and cleaving activities of these proteolytic enzymes (Visse and Nagase, 2003).

Different proteinases are in charge of active extracellular enzymatic function, especially the MMP family that plays an important role in the complicated process of dentinogenesis. There is a general consensus that MMPs in the dentin matrix are important in tooth development and dentinal caries. Collagen degradation during caries progression, particularly in root caries, occurs in the absence of a contribution from bacterial and salivary MMPs when the complete enamel cavosurface margins are sealed (Tjäderhane et al., 1998a; van Strijp et al., 2003; Sorsa et al., 2004; Chaussain-Miller et al., 2006). Except for the inflammation of dental pulp and progression of caries lesions (Chaussain-Miller et al., 2006), MMPs are involved in autodegradation of the dentin matrix exposed during dentin bonding procedures (Pashley et al., 2004).

The odontoblasts in developed human teeth synthesize and release several MMPs, including collagenase-2 (MMP-8) (Palosaari et al., 2000), gelatinases (MMP-2 and -9) (Tjäderhane et al., 1998b), membrane-bound MMP-14 (MT1-MMP) (Palosaari et al., 2002), enamelysin (MMP-20) (Sulkala et al., 2002) and cathepsin D (Linde and Persliden, 1977). The latent and active forms of gelatinolytic species (e.g. MMP-2, MMP-9 and MMP-10) have been identified in extraction from mineralized and demineralized human dentin taking advantage of gelatin zymography and Western blots (van Strijp et al., 2003; Mazzoni et al., 2007; Sulkala et al., 2007). The activated form of MMP-2 migrating at $66 \mathrm{kDa}$ is derived from the zymogen 
proMMP-2 (72 kDa). MMP-9 is identified by the zymogen proMMP-9 migrating at $92 \mathrm{kDa}$ and an activated form of MMP-9 migrating at $86 \mathrm{kDa}$. It has been shown that even mineralized dentin powder exhibits intrinsic collagenolytic activity (Hashimoto, 2005).

In general, collagen can be degraded into 3/41/4-length peptides by human collagenases, such as MMP-1, MMP-8 and MMP-13, which can then be subsequently degraded by the gelatinases MMP-2 and MMP-9 (Chaussain-Miller et al., 2006).

The distribution of MMP-2 and MMP-9 in different tissues was identified in a recent study by means of an immunohistochemical approach using monoclonal antibodies. Partially decalcified human dentin was examined using field emission in-lensscanning electron microscopy (FEI-SEM), and demineralized human dentin using transmission electron microscopy (TEM). The morphological localization of MMP-2 and MMP-9 within the ECM was also determined (Mazzoni et al., 2009). Both MMP-2 and MMP-9 were localized mainly in the intertubular collagen fibril network and along the collagen fibrils. Boushell et al. showed that MMP-2 is present throughout human coronal dentin, but is most intense in a 9-10 $\mu \mathrm{m}$ zone adjacent to the dentinoenamel junction (DEJ) and in a 90-200 $\mu \mathrm{m}$ wide zone adjacent to the pre-dentin (Boushell et al., 2008).

\section{Release and activation of MMPs and their potential roles in dentin bonding}

Metal ions, such as calcium and zinc, are required for the catalytic activity of MMPs. Most MMPs are synthesized and released from odontoblasts in the form of proenzymes (Tjäderhane et al., 2001), requiring activation to degrade ECM components through a so-called cysteine switch, a highly conserved zinc-binding active site domain-catalytic domain. MMPs can be activated in a low $\mathrm{pH}$ microenvironment (Tjäderhane et al., 1998a). pH changes may alter the conformation of the propeptide. This induces the cysteine switch and represents a key step in the activation of the enzyme (van Wart and Birkedal-Hansen, 1990).

With respect to caries, host-derived MMPs may be activated under acidic $\mathrm{pH}$ created by lactate which is produced by cariogenic bacteria (Chaussain-Miller et al., 2006). Acids released from bacteria decrease $\mathrm{pH}$, and further activate hostderived pro-MMPs from dentin during caries processes (Chaussain-Miller et al., 2006). The activated neutral proteinases can digest the demineralized dentin matrix after $\mathrm{pH}$ neutralization by salivary buffers (Chaussain-Miller et al., 2006).

The intrinsic MMPs in dentin can be activated also by the acidic properties of adhesive systems. Mild acids are known to activate dentin MMPs (Nishitani et al., 2006; Tay et al., 2006). Etchand-rinse adhesives (Mazzoni et al., 2006) and self-etching adhesives (Nishitani et al., 2006) have been confirmed to have the ability to reactivate gelatinases (MMP-2 and MMP-9) and collagenase in demineralized dentin powder (Mazzoni et al., 2007). Using zymography, Lehmann et al. showed that the expression of MMP-2 and pro-MMP-9 in odontblasts increased after self-etching adhesive was used in the treatment of dentin cavities when pulp was present (Lehmann et al., 2009). The result was verified by immunohistochemistry. These results show that the release of MMPs can be stimulated by self-etching adhesives from the dentin-pulp complex and, more precisely, from odontoblasts. This may account for the participation of odontoblasts in collagen degradation of bonding interfaces. The evidence of collagenolytic /gelatinolytic activities in partially demineralized dentin collagen matrices also provides indirect proof of the existence of MMPs in human dentin (Nishitani et al., 2006).

Self-etching adhesives may activate latent MMPs to near-maximum levels, causing the degradation of long-term dentin-resin bonds (Nishitani et al., 2006). Recent in vitro and in vivo findings indicate that the application of acidic primers or dental bonding systems containing acidic monomers promotes the activation of latent MMPs (Mazzoni et al., 2006; Nishitani et al., 2006). The self-etching dental adhesives routinely used clinically are acidic (pH 1.5-2.7) and have the ability to activate MMPs in dentin, without denaturing these enzymes during the bonding procedure, resulting in a 14- to 15 -fold increase in collagenolytic activities. Finally, collagen fibrils in resin-dentin interfaces infiltrated suboptimally by adhesive, are prone to proteolytic degra- 
dation (Breschi et al., 2008), and are degraded by the active enzymes.

However, one study revealed that monomers with lower $\mathrm{pH}$ values create less MMP activity, and that there is a considerable correlation between $\mathrm{pH}$ and gelatinolytic activity (Nishitani et al., 2006). Also, the collagenolytic activity in mineralized dentin powder treated with $37 \%$ (by weight) phosphoric acid gel for 15 seconds was reduced by $65 \%$ (Pashley et al., 2004). The low pH of $37 \%$ phosphoric acid gel ( $\mathrm{pH}$ 0.17) was thought not only to demineralize the dentin powder and reactivate MMP but also to denature these enzymes (Perdigao et al., 1996). Therefore, the net MMP activity was very low (Nishitani et al., 2006). However, the $\mathrm{pH}$ values of many commercial simplified adhesives containing acidic monomers are between 1 and 2, which can demineralize dentin but are not acidic enough to denature MMPs. Therefore, latent MMPs can be activated by selfetch adhesives. This can contribute to the degradation of collagen at the bonding interface, which may reduce resin-dentin bonding strength over the long term (Nishitani et al., 2006).

Mazzoni et al. confirmed that the simplified etch-and-rinse adhesives also played a potential role in dentin proteolytic activities quantified before and after sequential applications of the phosphoric acid-etchant and an etch-and-rinse adhesive (Mazzoni et al., 2006). Phosphoric acid etching can decrease MMP activity because of the low $\mathrm{pH}$ value (Pashley et al., 2004), but the simplified etch-and-rinse adhesives can reactivate the intrinsic MMPs trapped within dentin. This may be the reason why the degradation of hybrid layers takes place after using simplified etch-and-rinse adhesives in vivo and in vitro (Hebling et al., 2005; Mazzoni et al., 2006).

Several factors reduce the longevity of dentin bonding. For example: the application of simplified adhesives, insufficient resin infiltration (Hashimoto et al., 2000; Hashimoto et al., 2002; Hashimoto et al., 2003b; Hashimoto et al., 2003c; Tay and Pashley, 2003), sub-optimal polymerization (Eick et al., 1997; Cadenaro et al., 2005; Cadenaro et al., 2006), degradation of resin components (Hashimoto et al., 2000; De Munck et al., 2005; Tay and Pashley, 2003), high permeability of the bonded interface and activation of endogenous collageno- lytic enzymes.

After superficial demineralization, the resin adhesive infiltrates the ECM of dentin and polymerizes in situ forming a so-called "hybrid layer". A successful long-term dentin-resin bond depends on the formation of a homogenous and strong hybrid layer created by the perfect infiltration of resin monomers into dentin substrate (Nakabayashi et al., 1982). Morphological evidence of hydrolytic degradation of collagen in hybrid layers after an extended period has been presented in several studies (Sano et al., 1999; Hashimoto et al., 2000; Hashimoto et al., 2002; Hashimoto et al., 2003b; Hashimoto et al., 2003c). Degradation of collagen fibrils in the hybrid layer suggests the presence of exposed collagen fibrils. This was confirmed by the identification of uncovered collagen fibrils at the bottom of the hybrid layer owing to imperfect resin impregnation of the demineralized dentin matrix (Spencer et al., 2004). Although self-etch adhesive systems have the ability to etch and prime simultaneously, they also can suffer from deficient resin infiltration (Sano et al., 1995).

In addition to imperfect infiltration of the dentin substrate, water is another indispensable factor for the hydrolytic function of MMPs. As MMPs are hydrolases, the existence of water (e.g., artificial saliva) is necessary for them to hydrolyze peptide bonds in collagen resulting in the degradation of the resin-dentin interface (Sulkala et al., 2001; Chaussain-Miller et al., 2006; Carrilho et al., 2008). A recent study confirmed the important role of water in resin-dentin interface degradation, by showing no loss of dentin-adhesive bond strength with time when mineral oil was used as a storage medium instead of water (Oliveira et al., 2004). This is in agreement with another study showing that collagen in partially demineralized dentin stored in artificial saliva was almost devastated after 250 days, but this could be prevented by storage in mineral oil (Pashley et al., 2004).

Resin elution also occurs through nanoleakage channels over time from unstable polymeric hydrogels within the hybrid layer (Wang and Spencer, 2003). This can uncover collagen fibrils so that they are susceptible to hydrolysis by proteolytic enzymes released from the dentin matrix and odontoblast secretion. This may be the reason for the almost total disappearance of parts of the 
hybrid layer in resin-dentin bonding after 4 years water storage (De Munck et al., 2003). The breakdown of collagen may increase the water content, one of the major causes of further collagen degradation at the bonded interface, inducing deterioration of long-term dentin bonding.

In conclusion, host-derived MMPs were shown to take part in the long-term degradation of collagen fibrils infiltrated suboptimally by the adhesive agent during the formation of the hybrid layer. This degradation endangers the integrity of the interface created by infiltration of demineralized dentin substrate with adhesive resin monomers (Pashley et al., 2004; Mazzoni et al., 2006; Nishitani et al., 2006; Carrilho et al., 2007a; Breschi et al., 2008). In vitro, the release and activation of intrinsic proteinases have been confirmed to be responsible for the hydrolysis of dentin collagen within the hybrid layer owing to incomplete infiltration of resin adhesives (Pashley et al., 2004; Tay et al., 2006; Carrilho et al., 2007a). Complete resin infiltration into the dentin matrix is recommended to achieve the goal of bonding processes. Envelopment of collagen with resin protects it from degradation (Vargas et al., 1997; Hashimoto et al., 2003b). If there is no unexposed collagen unprotected by adhesive resins, degradation of the hybrid layer may no longer be a problem. If the adhesive resins can seal the dentin matrix from water, they may protect the collagen from hydrolysis by host-derived MMPs (Pashley et al., 2004; Hosaka et al., 2009; Sauro et al., 2009). However, how long this kind of sequestration lasts is still not clear.

\section{Inhibiting degradation of collagen in dentin -MMP inhibitors}

Major concerns have been expressed recently regarding the long-term dentin bonding of resin adhesives. Long-term bonding is threatened by disaggregation of the hybrid layer owing mainly to the activation of dentin MMPs. Several methods have been suggested to achieve superior infiltration of monomers, to inhibit the breakdown of collagen fibrils, and to reduce aging water sorption, for example: using hydrophobic adhesives following the use of all-in-one adhesive primers, which have a low level of water sorption and solubility (Ito et al., 2005; King et al., 2005), application of multiple layers (Pashley et al., 2002; Hashimoto et al., 2005), lengthening the curing time (Cadenaro et al., 2005; Cadenaro et al., 2006), increasing solvent evaporation (van Landuyt et al., 2005) and using electric current (Pasquantonio et al., 2007).

Alternatively, it would be advantageous from a clinical perspective to be able to inhibit the breakdown of deficient resin-impregnation collagen fibrils by host-derived MMPs in the dentinal hybrid layer. Tissue inhibitors of metalloproteinases (TIMPs) are the major endogenous inhibitors of MMPs. The balance between MMPs and TIMPs, which is important for tissue ECM remodelling, is destroyed in many diseases (Wojtowicz-Praga et al., 1997; Overall and Lopez-Otin, 2002). Both increasing the local concentration of TIMPs and application of extrinsic MMPs inhibitors can be used to recover the MMP-TIMP balance and thereby block disease progression.

Protease inhibitors as additional primers might be recommended to inhibit the intrinsic collagenolytic activity of human dentin, to reduce the aging of bonding interfaces and to increase the stability of the dentinal collagen fibrils within the hybrid layer. This is essential in dentin bonding and may be achieved by inhibiting activated host-derived dentin enzymes which are liable for the breakage of dentin collagen fibrils without bacteria (Hebling et al., 2005; Brackett et al., 2007; Carrilho et al., 2007b).

Some studies have shown that a low collagenase activity can be detected in partially mineralized human dentin powder using fluorescein-labeled collagen. This activity is thought to simulate collagen degradation in demineralized dentin over a 250-day time period in vitro (Figure 1D) (Pashley et al., 2004) and hybrid layer degradation in vivo (Hebling et al., 2005a). Dentin matrix degradation in vitro over a 250 -day time period can be totally inhibited by protease inhibitors within an incubation medium (Figure 1E), and collagenolytic activity of mineralized dentin powder is reduced by $73 \%$ (Pashley et al., 2004). This may be direct proof that MMP inhibitors can protect collagen fibrils and improve dentin bonding durability. However, it may also be indirect evidence of the existence of MMPs in partially demineralized dentin and of 
their role in dentin matrix breakdown.

The activities of endogenous collagenase and gelatinase derived from demineralized dentin are thought to induce the degradation of bonded dentin matrix in the hybrid layer. Therefore, the application of some specific MMP inhibitors which can suppress dentin collagenolytic and gelatinolytic activities (Pashley et al., 2004), such as EDTA (ethylene diaminetetraacetic acid; Martin-De Las Heras et al., 2000) and chlorhexidine (Hebling et al., 2005; Carrilho et al., 2007a; Carrilho et al., 2007b), were recommended to restrict the deterioration of hybrid layers. Even very low chlorhexidine concentrations showed complete MMP inhibition (Gendron et al., 1999).

\section{Chlorhexidine}

Chlorhexidine (CHX) is a broad-spectrum antimicrobial agent used widely in the treatment of oral diseases. Its antibacterial efficacy is comparable to that of sodium hypochlorite. Recently,
CHX has been found to have desirable MMPinhibition properties (MMP-2, -8 and -9) even at low concentrations (Gendron et al., 1999), possibly resulting from its $\mathrm{Zn}^{2+}$ cation-chelating property (Gendron et al., 1999). The molecular formula of chlorhexidine is shown in Figure 3.

CHX within concentrations ranging from $0.05 \%$ to $2 \%$ has antimicrobial activity against Enterococcus faecalis (Gomes et al., 2003). Besides its antimicrobial properties, CHX is applied to treat dentin prior to the use of etch-and-rinse adhesives to reduce the breakdown of collagen fibrils (Pashley et al., 2004). The minimum concentration of CHX that gives complete inhibition of MMP-9 activity seems to be $0.002 \%$. However, MMP-2 activity is much more sensitive, being inhibited by $0.000,1 \%$ CHX. MMP-8 can be inhibited at a CHX concentration of $0.02 \%$ (Gendron et al., 1999). It was also shown that the collagenolytic activity of dentin powder could be inhibited to near zero level by treatment with $0.2 \%$ CHX for 60 seconds (Pashley et al., 2004; Tay et al., 2006).

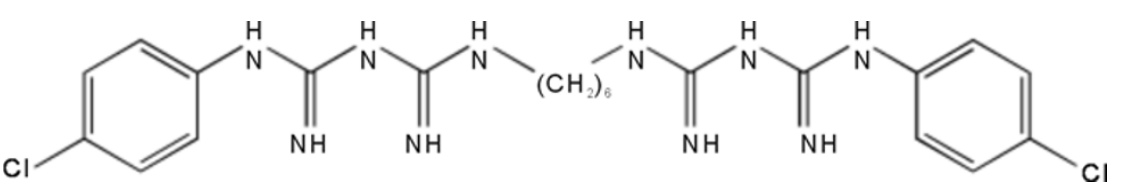

Figure 3 Molecular formula of CHX
After CHX application, the collagen fibril networks of the hybrid layer retained their normal structure and integrity but without CHX application they showed progressive degradation (Hebling et al., 2005). Also, microtensile bond strength after water storage for 6 months was higher with the application of CHX as an additional primer in an etch-and-rinse adhesive than without CHX application (Carrilho et al., 2007b). Application of CHX before use of adhesives has no influence on the short-term bonding strength of etch-and-rinse adhesives (Teronen et al., 1997; Bocangel, 2000).

The application of CHX to acid-etched human dentin can save the collagen fibrils in the hybrid layer when etch-and-rinse dentin bonding is used (King et al., 2005; Mazzoni et al., 2006; Brackett et al., 2009). This provides indirect proof of the involvement of MMPs in the degradation of collagen in the hybrid layer and the resulting decrease in bond strength over time.

Although CHX has become the most popular
MMP inhibitor in preventing the degradation of the dentin matrix (Gendron et al., 1999; Pashley et al., 2004), it is not known how long the inhibition effect will last.

\section{Other MMP inhibitors}

Synthetic peptidomimetic inhibitors with zinc chelator properties can be used to inhibit the active site of the catalytic domain, thus inhibiting the activity of MMPs. To inhibit the degradation of collagen fibrils resulting from MMPs, some investigators suggested first, to use mild self-etching adhesives to only partially expose these fibrils, and second, to incorporate appropriate degradation inhibitors into the bonding procedure. Several newly developed agents, for example, Marimastat (Wojtowicz-Praga et al., 1997) and CT 1166 (Fanchon et al., 2004), provide effective inhibition of MMPs. Another potent anti-MMP, Ilomastat (also called galardin) was shown to inhibit ortho- 
dontic tooth movement in rats (Holiday et al., 2003).

Tetracyclines are commonly used as antibiotics in the treatment of periodontitis (Ryan et al., 1996). It has been shown both in vitro and in vivo that tetracyclines and their semi-synthetic forms, doxicycline and minocycline, have the ability to inhibit MMP-1, MMP-2 and MMP-12 (Golub et al., 1995). Another kind of effective and safe MMP inhibitor, is non-antimicrobial chemically modified tetracyclines (CMTs), which inhibit both the release and activity of MMPs through $\mathrm{Ca}^{2+}$ chelation (Golub et al., 1998).

It has also been discovered that zoledronate, a third generation bisphosphonate, has the ability to inhibit MMP proteolytic activities (Teronen et al., 1997; Boissier et al., 2000). CMTs and their analogues, which are currently being assessed in clinical trials for the treatment of cancer, may offer promising methods for achieving durable dentin bonding.

Green tea polyphenols, especially epigallocatechin gallate (EGCG), have been revealed to be able to inhibit the activation of proMMP-2, MMP-2 and MMP-9 (Demeule et al., 2000; Garbisa et al., 2001; Sartor et al., 2002). Soya bean unsaponifiables and avocado (Kut et al., 1998), and oleic acid (Huet et al., 2004) show effective MMPinhibition in vitro. Gaultier et al. demonstrated that LU 105, a natural extract from seeds of Lupinus albus, can decrease the expression of both MMP-9 and MMP-2 by gingival fibroblasts in periodontal diseases (Gaultier et al., 2003). The active extract from elm cortex, procyanidin oligomer, has shown a similar inhibitory effect on host-derived MMPs (Song et al., 2003).

\section{Conclusions}

The degradation of collagen fibrils in situ within an incompletely infiltrated hybrid layer has been shown to have an adverse effect on the remineralization of unprotected dentin collagen in vivo (Mukai and ten Cate, 2002; Ferrari and Tay, 2003). MMP inhibitors, which prevent collagen degradation during dentinal caries, should be recommended for use in the natural healing of carious dentin matrix through further remineralization. During the dentin bonding process, it would be advantageous to apply MMP inhibitors that have the ability not only to inhibit the breakdown of dentin collagen within the hybrid layers, thereby improving the durability of dentin bonding, but also to prevent the occurrence of secondary caries around restorations.

New bonding systems should provide durable MMP-inhibitory functionality to preserve the integrity of the hybrid layer and to improve dentin bonding durability of adhesive restorations.

\section{References}

Armstrong SR, Keller JC, Boyer DB (2001). Mode of failure in the dentin-adhesive resin-resin composite bonded joint as determined by strength-based (muTBS) and fracture-based (CNSB) mechanical testing. Dent Mater, 17(3): 201-210.

Birkedal-Hansen H (1993). Role of matrix metalloproteinases in human periodontal diseases. $J$ Periodontol, 64(Suppl 5): 474-484.

Birkedal-Hansen H, Moore WG, Bodden MK, Windsor LJ, Birkedal-Hansen B, DeCarlo A, et al. (1993). Matrix metalloproteinases: a review. Crit Rev Oral Biol Med, 4(2): 197-250.

Bocangel JSK, Vargas AG, DeMarco FF, Matson E (2000). Influence of disinfectant solutions on the tensile bond strength of a fourth generation dentin bonding agent. Pesq Odont Bras, 14(2): 107-111.

Boissier S, Ferreras M, Peyruchaud O, Magnetto S, Ebetino $\mathrm{FH}$, Colombel M, et al. (2000). Bisphosphonates inhibit breast and prostate carcinoma cell invasion, an early event in the formation of bone metastases. Cancer Res, 60(11): 2949-2954.

Boushell LW, Kaku M, Mochida Y, Bagnell R, Yamauchi M (2008). Immunohistochemical localization of matrixmetalloproteinase-2 in human coronal dentin. Arch Oral Biol, 53(2):109-116.

Brackett MG, Tay FR, Brackett WW, Dib A, Dipp FA, Sui $\mathrm{M}$, et al. (2009). In vivo chlorhexidine stabilization of hybrid layers of an acetone-based dentin adhesive. Oper Dent, 34(4): 381-385.

Brackett WW, Tay FR, Brackett MG, Dib A, Sword RJ, Pashley DH (2007). The effect of chlorhexidine on dentin hybrid layers in vivo. Oper Dent, 32(2):107-111.

Breschi L, Lopes M, Gobbi P, Mazzotti G, Falconi M, Perdigao J (2002). Dentin proteoglycans: an immunocytochemical FEISEM study. J Biomed Mater Res, 61(1): 40-46. 
Breschi L, Mazzoni A, Ruggeri A, Cadenaro M, Di Lenarda R, De Stefano Dorigo E (2008). Dental adhesion review: aging and stability of the bonded interface. Dent Mater, 24(1): 90-101.

Breschi L, Perdigao J, Gobbi P, Mazzotti G, Falconi M, Lopes M (2003). Immunocytochemical identification of type I collagen in acid-etched dentin. $J$ Biomed Mater Res A, 66(4): 764-769.

Breschi L, Prati C, Gobbi P, Pashley D, Mazzotti G, Teti G, et al. (2004). Immunohistochemical analysis of collagen fibrils within the hybrid layer: a FEISEM study. Oper Dent, 29(5): 538-546.

Brinckerhoff CE, Matrisian LM (2002). Matrix metalloproteinases: a tail of a frog that became a prince. Nat Rev Mol Cell Biol, 3(3): 207-214.

Butler WT, Brunn JC, Qin C (2003). Dentin extracellular matrix (ECM) proteins: comparison to bone ECM and contribution to dynamics of dentinogenesis. Connect Tissue Res, 44(Suppl 1): 171-178.

Cadenaro M, Antoniolli F, Sauro S, Tay FR, Di Lenarda R, Prati C, et al. (2005). Degree of conversion and permeability of dental adhesives. Eur J Oral Sci, 113(6): 525-530.

Cadenaro M, Breschi L, Antoniolli F, Mazzoni A, Di Lenarda R (2006). Influence of whitening on the degree of conversion of dental adhesives on dentin. Eur J Oral Sci, 114(3): 257-262.

Carrilho MR, Carvalho RM, de Goes MF, di Hipolito V, Geraldeli S, Tay FR, et al. (2007b). Chlorhexidine preserves dentin bond in vitro. J Dent Res, 86(1): 90-94.

Carrilho MR, Geraldeli S, Tay F, de Goes MF, Carvalho RM, Tjaderhane L, et al. (2007a). In vivo preservation of the hybrid layer by chlorhexidine. $J$ Dent Res, 86(6): 529-533.

Chaussain-Miller C, Fioretti F, Goldberg M, Menashi S (2006). The role of matrix metalloproteinases (MMPs) in human caries. J Dent Res, 85(1): 22-32.

Dayan D, Binderman I, Mechanic GL (1983). A preliminary study of activation of collagenase in carious human dentine matrix. Arch Oral Biol, 28(2): 185187.

De Munck J, van Landuyt K, Peumans M, Poitevin A, Lambrechts P, Braem M, et al. (2005). A critical review of the durability of adhesion to tooth tissue: methods and results. J Dent Res, 84(2): 118-132.

De Munck J, van Meerbeek B, Yoshida Y, Inoue S, Vargas M, Suzuki K, et al. (2003). Four-year water degradation of total-etch adhesives bonded to dentin. J Dent
Res, 82(2): 136-140.

Demeule M, Brossard M, Page M, Gingras D, Beliveau R (2000). Matrix metalloproteinase inhibition by green tea catechins. Biochim Biophys Acta, 1478(1):51-60.

Eick JD, Gwinnett AJ, Pashley DH, Robinson SJ (1997). Current concepts on adhesion to dentin. Crit Rev Oral Biol Med, 8(3): 306-335.

Embery G, Hall R, Waddington R, Septier D, Goldberg M (2001). Proteoglycans in dentinogenesis. Crit Rev Oral Biol Med, 12(4): 331-349.

Fanchon S, Bourd K, Septier D, Everts V, Beertsen W, Menashi S, et al. (2004). Involvement of matrix metalloproteinases in the onset of dentin mineralization. Eur J Oral Sci, 112(2): 171-176.

Ferrari M, Tay FR (2003). Technique sensitivity in bonding to vital, acid-etched dentin. Oper Dent, 28(1): 3-8.

Garbisa S, Sartor L, Biggin S, Salvato B, Benelli R, Albini A (2001). Tumor gelatinases and invasion inhibited by the green tea flavanol epigallocatechin-3-gallate. Cancer, 91(4): 822-832.

Gaultier F, Foucault-Bertaud A, Lamy E, Ejeil AL, Dridi SM, Piccardi N, et al. (2003). Effects of a vegetable extract from Lupinus albus (LU105) on the production of matrix metalloproteinases (MMP1, MMP2, MMP9) and tissue inhibitor of metalloproteinases (TIMP1, TIMP2) by human gingival fibroblasts in culture. Clin Oral Investig, 7(4): 198-205.

Gendron R, Grenier D, Sorsa T, Mayrand D (1999). Inhibition of the activities of matrix metalloproteinases 2, 8, and 9 by chlorhexidine. Clin Diagn Lab Immunol, 6(3): 437-439.

Goldberg M, Takagi M (1993). Dentine proteoglycans: composition, ultrastructure and functions. Histochem $J$, 25(11): 781-806.

Golub LM, Lee HM, Ryan ME, Giannobile WV, Payne J, Sorsa T (1998). Tetracyclines inhibit connective tissue breakdown by multiple non-antimicrobial mechanisms. Adv Dent Res, 12(2): 12-26.

Golub LM, Sorsa T, Lee HM, Ciancio S, Sorbi D, Ramamurthy NS, et al. (1995). Doxycycline inhibits neutrophil (PMN)-type matrix metalloproteinases in human adult periodontitis gingiva. J Clin Periodontol, 22(2): 100-109.

Gomes BP, Souza SF, Ferraz CC, Teixeira FB, Zaia AA, Valdrighi L, et al. (2003). Effectiveness of 2\% chlorhexidine gel and calcium hydroxide against Enterococcus faecalis in bovine root dentine in vitro. Int Endod J, 36(4): 267-275. 
Hashimoto M, De Munck J, Ito S, Sano H, Kaga M, Oguchi $\mathrm{H}$, et al. (2004). In vitro effect of nanoleakage expression on resin-dentin bond strengths analyzed by microtensile bond test, SEM/EDX and TEM. Biomaterials, 25(25): 5565-5574.

Hashimoto M, Ohno H, Kaga M, Endo K, Sano H, Oguchi $\mathrm{H}$ (2000). In vivo degradation of resin-dentin bonds in humans over 1 to 3 years. J Dent Res, 79(6): 13851391.

Hashimoto M, Ohno H, Sano H, Kaga M, Oguchi H (2003a). In vitro degradation of resin-dentin bonds analyzed by microtensile bond test, scanning and transmission electron microscopy. Biomaterials, 24(21): 3795-3803.

Hashimoto M, Ohno H, Sano H, Kaga M, Oguchi H (2003b). Degradation patterns of different adhesives and bonding procedures. J Biomed Mater Res B Appl Biomater, 66(1): 324-330.

Hashimoto M, Ohno H, Sano H, Tay FR, Kaga M, Kudou Y, et al. (2002). Micromorphological changes in resindentin bonds after 1 year of water storage. $J$ Biomed Mater Res, 63(3): 306-311.

Hashimoto M, Tay FR, Ito S, Sano H, Kaga M, Pashley DH (2005). Permeability of adhesive resin films. $J$ Biomed Mater Res B Appl Biomater, 74(2): 699-705.

Hashimoto M, Tay FR, Ito S, Sano H, Pashley DH (2005). Effect of chlorhexidine on MMP activity of human dentin. IADR/AADR/CADR 83rd General Session.

Hashimoto M, Tay FR, Ohno H, Sano H, Kaga M, Yiu C, et al. (2003c). SEM and TEM analysis of water degradation of human dentinal collagen. $J$ Biomed Mater Res B Appl Biomater, 66(1): 287-298.

Hebling J, Pashley DH, Tjaderhane L, Tay FR (2005). Chlorhexidine arrests subclinical degradation of dentin hybrid layers in vivo. J Dent Res, 84(8): 741-746.

Holiday LS, Vakani A, Archer L, Dolce C (2003). Effects of matrix metalloproteinase inhibitors on bone resorption and orthodontic tooth movement. J Dent Res, 82(9): 687-691.

Hosaka K, Nishitani Y, Tagami J, Yoshiyama M, Brackett WW, Agee KA, et al. (2009). Durability of resindentin bonds to water $v s$. ethanol-saturated dentin. $J$ Dent Res, 88(2): 146-151.

Huet E, Cauchard JH, Berton A, Robinet A, Decarme M, Hornebeck W, et al. (2004). Inhibition of plasminmediated prostromelysin-1 activation by interaction of long chain unsaturated fatty acids with kringle 5 . Biochem Pharmacol, 67(4): 643-654.

Ito S, Hashimoto M, Wadgaonkar B, Svizero N, Carvalho
RM, Yiu C, et al. (2005). Effects of resin hydrophilicity on water sorption and changes in modulus of elasticity. Biomaterials, 26(33): 6449-6459.

King NM, Tay FR, Pashley DH, Hashimoto M, Ito S, Brackett WW, et al. (2005). Conversion of one-step to two-step self-etch adhesives for improved efficacy and extended application. Am J Dent, 18(2): 126-134.

Kut C, Assoumou A, Dridi M, Bonnefoix M, Gogly B, Pellat B, et al. (1998). Morphometric analysis of human gingival elastic fibres degradation by human leukocyte elastase protective effect of avocado and soybean unsaponifiables (ASU). Pathol Biol (Paris), 46(7): 571-576.

Lee W, Aitken S, Sodek J, McCulloch CA (1995). Evidence of a direct relationship between neutrophil collagenase activity and periodontal tissue destruction in vivo: role of active enzyme in human periodontitis. $J$ Periodontal Res, 30(1): 23-33.

Lehmann N, Debret R, Romeas A, Magloire H, Degrange M, Bleicher F, et al. (2009). Self-etching increases matrix metalloproteinase expression in the dentin-pulp complex. J Dent Res, 88(1): 77-82.

Linde A (1989). Dentin matrix proteins: composition and possible functions in calcification. Anat Rec, 224(2): 154-166.

Linde A, Goldberg M (1993). Dentinogenesis. Crit Rev Oral Biol Med, 4(5): 679-728.

Linde A, Persliden B (1977). Cathepsin D activity in isolated odontoblasts. Calcif Tissue Res, 23(1): 33-38.

Lynch CC, Matrisian LM (2002). Matrix metalloproteinases in tumor-host cell communication. Differentiation, 70(9/10): 561-573.

Marshall GW Jr, Marshall SJ, Kinney JH, Balooch M (1997). The dentin substrate: structure and properties related to bonding. $J$ Dent, 25(6): 441-458.

Martin-De Las Heras S, Valenzuela A, Overall CM (2000). The matrix metalloproteinase gelatinase $\mathrm{A}$ in human dentine. Arch Oral Biol, 45(9): 757-765.

Mazzoni A, Mannello F, Tay FR, Tonti GA, Papa S, Mazzotti G, et al. (2007). Zymographic analysis and characterization of MMP-2 and -9 forms in human sound dentin. $J$ Dent Res, 86(5): 436-440.

Mazzoni A, Pashley DH, Nishitani Y, Breschi L, Mannello F, Tjaderhane L, et al. (2006). Reactivation of inactivated endogenous proteolytic activities in phosphoric acid-etched dentine by etch-and-rinse adhesives. Biomaterials, 27(25): 4470-4476.

Mazzoni A, Pashley DH, Tay FR, Gobbi P, Orsini G, Ruggeri A Jr, et al. (2009). Immunohistochemical 
identification of MMP-2 and MMP-9 in human dentin: correlative FEI-SEM/TEM analysis. $J$ Biomed Mater Res A, 88(3): 697-703.

Milan AM, Sugars RV, Embery G, Waddington RJ (2005). Modulation of collagen fibrillogenesis by dentinal proteoglycans. Calcif Tissue Int, 76(2): 127-135.

Moses KD, Butler WT, Qin C (2006). Immunohistochemical study of small integrin-binding ligand, $\mathrm{N}$-linked glycoproteins in reactionary dentin of rat molars at different ages. Eur J Oral Sci, 114(3): 216-222.

Mukai Y, ten Cate JM (2002). Remineralization of advanced root dentin lesions in vitro. Caries Res, 36(4): 275280.

Nagase H, Woessner JF Jr (1999). Matrix metalloproteinases. J Biol Chem, 274(31): 21491-21494.

Nishitani Y, Yoshiyama M, Wadgaonkar B, Breschi L, Mannello F, Mazzoni A, et al. (2006). Activation of gelatinolytic/collagenolytic activity in dentin by selfetching adhesives. Eur J Oral Sci, 114(2): 160-166.

Oliveira SS, Marshall SJ, Habelitz S, Gansky SA, Wilson RS, Marshall GW Jr (2004). The effect of a selfetching primer on the continuous demineralization of dentin. Eur J Oral Sci, 112(4): 376-383.

Overall CM, Lopez-Otin C (2002). Strategies for MMP inhibition in cancer: innovations for the post-trial era. Nat Rev Cancer, 2(9): 657-672.

Palosaari H, Ding Y, Larmas M, Sorsa T, Bartlett JD, Salo $\mathrm{T}$, et al. (2002). Regulation and interactions of MT1MMP and MMP-20 in human odontoblasts and pulp tissue in vitro. $J$ Dent Res, 81(5): 354-359.

Palosaari H, Wahlgren J, Larmas M, Ronka H, Sorsa T, Salo T, et al. (2000). The expression of MMP-8 in human odontoblasts and dental pulp cells is downregulated by TGF-beta1. J Dent Res, 79(1): 77-84.

Pashley DH, Tay FR, Yiu C, Hashimoto M, Breschi L, Carvalho RM, et al. (2004). Collagen degradation by host-derived enzymes during aging. J Dent Res, 83(3): 216-221.

Pashley EL, Agee KA, Pashley DH, Tay FR (2002). Effects of one versus two applications of an unfilled, all-in-one adhesive on dentine bonding. J Dent, 30(2/3): 83-90.

Pasquantonio G, Tay FR, Mazzoni A, Suppa P, Ruggeri A Jr, Falconi M, et al. (2007). Electric device improves bonds of simplified etch-and-rinse adhesives. Dent Mater, 23(4): 513-518.

Perdigao J, Lambrechts P, van Meerbeek B, Tome AR, Vanherle G, Lopes AB (1996). Morphological field
emission-SEM study of the effect of six phosphoric acid etching agents on human dentin. Dent Mater, 12(4): 262-271.

Ryan ME, Ramamurthy S, Golub LM (1996). Matrix metalloproteinases and their inhibition in periodontal treatment. Curr Opin Periodontol, 3: 85-96.

Sano H, Takatsu T, Ciucchi B, Horner JA, Matthews WG, Pashley DH (1995). Nanoleakage: leakage within the hybrid layer. Oper Dent, 20(1): 18-25.

Sano H, Yoshikawa T, Pereira PN, Kanemura N, Morigami M, Tagami J, et al. (1999). Long-term durability of dentin bonds made with a self-etching primer, in vivo. J Dent Res, 78(4): 906-911.

Sartor L, Pezzato E, Dell'Aica I, Caniato R, Biggin S, Garbisa S (2002). Inhibition of matrix-proteases by polyphenols: chemical insights for anti-inflammatory and anti-invasion drug design. Biochem Pharmacol, 64(2): 229-237.

Sauro S, Watson TF, Mannocci F, Tay FR, Pashley DH (2009). Two-photon laser confocal microscopy study of resin-dentin interfaces created with water or ethanol wet-bonding technique: qualitative and quantitative micropermeability assessment. J Biomed Mater Res: Part B Appl Biomater, 90B: 327-337.

Song SE, Choi BK, Kim SN, Yoo YJ, Kim MM, Park SK, et al. (2003). Inhibitory effect of procyanidin oligomer from elm cortex on the matrix metalloproteinases and proteases of periodontopathogens. J Periodontal Res, 38(3): 282-289.

Sorsa T, Tjaderhane L, Salo T (2004). Matrix metalloproteinases (MMPs) in oral diseases. Oral Dis, 10(6): 311-318.

Sulkala M, Larmas M, Sorsa T, Salo T, Tjaderhane L (2002). The localization of matrix metalloproteinase -20 (MMP-20, enamelysin) in mature human teeth. $J$ Dent Res, 81(9): 603-607.

Sulkala M, Tervahartiala T, Sorsa T, Larmas M, Salo T, Tjaderhane L (2007). Matrix metalloproteinase- 8 (MMP-8) is the major collagenase in human dentin. Arch Oral Biol, 52(2): 121-127.

Takahashi A, Inoue S, Kawamoto C, Ominato R, Tanaka T, Sato $\mathrm{Y}$, et al. (2002). In vivo long-term durability of the bond to dentin using two adhesive systems. $J$ Adhes Dent, 4(2): 151-159.

Tay FR, Pashley DH (2003). Have dentin adhesives become too hydrophilic? J Can Dent Assoc, 69(11): 726-731.

Tay FR, Pashley DH, Loushine RJ, Weller RN, Monticelli F, Osorio R (2006). Self-etching adhesives increase 
collagenolytic activity in radicular dentin. $J$ Endod, 32(9): 862-868.

Tay FR, Pashley DH, Yoshiyama M (2002). Two modes of nanoleakage expression in single-step adhesives. $J$ Dent Res, 81(7): 472-476.

Teronen O, Konttinen YT, Lindqvist C, Salo T, Ingman T, Lauhio A, et al. (1997). Inhibition of matrix metalloproteinase-1 by dichloromethylene bisphosphonate (clodronate). Calcif Tissue Int, 61(1): 59-61.

Tjaderhane L, Larjava H, Sorsa T, Uitto VJ, Larmas M, Salo T (1998a). The activation and function of host matrix metalloproteinases in dentin matrix breakdown in caries lesions. J Dent Res, 77(8): 1622-1629.

Tjaderhane L, Palosaari H, Wahlgren J, Larmas M, Sorsa T, Salo T (2001). Human odontoblast culture method: the expression of collagen and matrix metalloproteinases (MMPs). Adv Dent Res, 15: 55-58.

Tjaderhane L, Salo T, Larjava H, Larmas M, Overall CM (1998b). A novel organ culture method to study the function of human odontoblasts in vitro: gelatinase expression by odontoblasts is differentially regulated by TGF-beta1. J Dent Res, 77(7): 1486-1496.

Toledano M, Perdigao J, Osorio E, Osorio R (2002). Influence of $\mathrm{NaOCl}$ deproteinization on shear bond strength in function of dentin depth. Am J Dent, 15(4): 252-255.

van Landuyt KL, De Munck J, Snauwaert J, Coutinho E, Poitevin A, Yoshida Y, et al. (2005). Monomer-solvent phase separation in one-step self-etch adhesives. $J$ Dent Res, 84(2): 183-188.

van Meerbeek B, De Munck J, Yoshida Y, Inoue S, Vargas
M, Vijay P, et al. (2003). Buonocore memorial lecture. Adhesion to enamel and dentin: current status and future challenges. Oper Dent, 28(3): 215-235.

van Strijp AJ, Jansen DC, DeGroot J, ten Cate JM, Everts V (2003). Host-derived proteinases and degradation of dentine collagen in situ. Caries Res, 37(1): 58-65.

van Wart HE, Birkedal-Hansen H (1990). The cysteine switch: a principle of regulation of metalloproteinase activity with potential applicability to the entire matrix metalloproteinase gene family. Proc Natl Acad Sci USA, 87(14): 5578-5582.

Vargas MA, Cobb DS, Denehy GE (1997). Interfacial micromorphology and shear bond strength of singlebottle primer/adhesives. Dent Mater, 13(5): 316-324.

Visse R, Nagase H (2003). Matrix metalloproteinases and tissue inhibitors of metalloproteinases: structure, function, and biochemistry. Circ Res, 92(8): 827-839.

Wang Y, Spencer P (2002). Quantifying adhesive penetration in adhesive/dentin interface using confocal Raman microspectroscopy. J Biomed Mater Res, 59(1): 46-55.

Wang Y, Spencer P (2003). Hybridization efficiency of the adhesive/dentin interface with wet bonding. J Dent Res, 82(2): 141-145.

Wojtowicz-Praga SM, Dickson RB, Hawkins MJ (1997). Matrix metalloproteinase inhibitors. Invest New Drugs, 15(1): 61-75.

Yang B, Adelung R, Ludwig K, Bossmann K, Pashley DH, Kern M (2005). Effect of structural change of collagen fibrils on the durability of dentin bonding. Biomaterials, 26(24): 5021-5031.

*Corresponding author: Matthias Kern

Address: Department of Prosthodontics, Propaedeutics and Dental Materials School of Dentistry, Christian-Albrechts University, Arnold-Heller-Str. 16, 24105 Kiel, Germany

Tel: $494315972874 \quad$ Fax: $494315972860 \quad$ E-mail: mkern@proth.uni-kiel.de 